\title{
The Relationship Between Serum 25[OH]D Concentration and Orthopaedic Infection: A Case-Control Study
}

This article was published in the following Dove Press journal: Orthopedic Research and Reviews

\author{
Alexander Zargaran' \\ David Zargaran ${ }^{2}$ \\ Alex Trompeter $\mathbb{D}^{3}$ \\ 'Department of Medicine, King's College \\ London, Guy's Campus, London SEI IUL, \\ UK; ${ }^{2}$ Department of Medicine, Imperial \\ College London, London SW7 2BU, UK; \\ ${ }^{3}$ Department of Orthopaedic Surgery, St \\ George's Hospital, London SWI7 \\ OQT, UK
}

Background: An estimated one in two healthy adults in the United Kingdom suffer from low levels of $25[\mathrm{OH}] \mathrm{D}$. Vitamin $\mathrm{D}$ is involved in modulating immune response, but there is less clarity over its role in orthopaedic infection. This study assesses the relationship between serum 25[OH]D concentration and orthopaedic infection.

Methods: A total of 205 patients in a tertiary referral centre for orthopaedic infection were included in the study. They were divided into groups based on their infection status, matched by age and gender. Data were statistically analysed to determine presence and direction of relationship.

Results: A total of 114 patients had an infection. There was no statistically significant difference in age or gender between the two groups. Mean serum 25[OH]D concentration was $39 \mathrm{nmol} / \mathrm{L}$ in the group with infection and $59 \mathrm{nmol} / \mathrm{L}$ in the group without an infection $(\mathrm{p}<0.01)$. Overall mean serum $25[\mathrm{OH}] \mathrm{D}$ concentration was $48 \mathrm{nmol} / \mathrm{L}$. There was a correlation between low serum 25 $[\mathrm{OH}] \mathrm{D}$ concentration and rate of infection (odds ratio, 5.94; 95\% confidence interval [CI], 3.24 to $10.92)$ with a bivariate correlation of $-0.338(\mathrm{p}<0.01)$.

Conclusion: This study demonstrates an association between low levels of serum 25[OH]D and increased orthopaedic infection. Orthopaedic inpatients suffered from vitamin D insufficiency, and there was a correlation between higher levels of serum 25[OH]D and lower rates of infection. This suggests that prophylactic supplementation of $25[\mathrm{OH}] \mathrm{D}$ may improve outcomes, and provides a foundation for randomized controlled trials to assess its effectiveness in practice.

Keywords: orthopaedic surgery, vitamin D, infection

\section{Introduction}

More than half of the healthy adult population in the United Kingdom suffers from vitamin D insufficiency, with 15.5\% suffering from vitamin D deficiency during winter and spring months. ${ }^{1}$ Vitamin D has an array of different functions in the human body, and is postulated to play a protective role against chronic diseases. Studies have demonstrated an association between low vitamin D levels and diabetes, ${ }^{2}$ cardiovascular diseases, ${ }^{3-5}$ cancers $^{6-9}$ and increased mortality. ${ }^{10}$

Vitamin D has been found to possess immunomodulatory properties in the human body, with a growing evidence-base indicating that supplementation is protective against infections including acute upper respiratory tract infections ${ }^{11}$ and infections in ICU patients. ${ }^{12}$ It is thought to have this function in part due to its role in the cathelicidin antimicrobial peptide pathway and induction of interleukin-10. ${ }^{13}$ However, there has been conflicting evidence regarding whether prophylactic
Correspondence: Alexander Zargaran Department of Medicine, Kings College London, Guy's Campus, Great Maze Pond, London SEI IUL, UK

Email alexander.zargaran@kcl.ac.uk 
supplementation of vitamin $\mathrm{D}$ is protective against infection. In a randomized, placebo controlled trial of 30 patients with sepsis of varying severity, Quraishi et $\mathrm{al}^{14}$ found that highdose supplementation with cholecalciferol was correlated with a decrease in concentration of inflammatory markers. Another randomized placebo controlled trial of 50 critically ill adults by Nair et $\mathrm{al}^{15}$ found no significant difference in concentration of inflammatory mediators between both groups over total follow-up period $(\mathrm{p}=0.53)$, despite shortterm fluctuations at 7 and 14 days. In addition, they found no statistically significant difference in mortality or length of stay between the groups.

Orthopaedic infection has historically been considered as a major contributor to healthcare associated infections, with 2821 cases reported in England in 2014/15 at a cost to hospitals of approximately $£ 16,341,295$ per annum. However, these costs do not include the necessary subsequent revision surgeries, costing at least an additional $£ 43,075,629$ per annum. ${ }^{19}$

This study aims to empirically quantify the vitamin D concentrations among orthopaedic patients in the UK, and to establish whether there is any correlation between low levels of vitamin D and orthopaedic infection.

\section{Methods}

Serum concentrations of 25[OH]D were collected prospectively from a total of 205 patients over a period of 12 months at a major trauma centre in the UK, which is also a tertiary referral centre for the management of orthopaedic infection. A period of 12 months was used to control for the confounding effect of seasonality on vitamin D concentration.

Patient demographic information and laboratory results were accessed via hospital records and all patient data were anonymized. No identifiable patient information was recorded, and no intervention was administered. The accepted definitions of vitamin D insufficiency as serum
$25[\mathrm{OH}] \mathrm{D}$ concentrations of between 25 and $50 \mathrm{nmol} / \mathrm{L}$ and deficiency as less than $25 \mathrm{nmol} / \mathrm{L}$ were used.

A convenience sample of adult (age $>18$ years) orthopaedic inpatients was taken, where children and patients not undergoing an orthopaedic procedure were excluded from the study. Patients were divided into two groups: one group of patients with a diagnosis of orthopaedic infection and another group of patients without a diagnosis of orthopaedic infection. Orthopaedic infection included Prosthetic Joint infection, Fracture related infection and Osteomyelitis. Patients who were on 25[OH]D supplementation during their hospital stay were excluded.

The two groups were matched based on their age and gender. Statistical analysis was conducted using IBM SPSS software. Descriptive statistics, independent samples t-tests, odds ratios and a bivariate correlation analysis were performed.

\section{Results}

A total of 205 patients were included in the study. The group with infection included 114 patients, while the group without infection consisted of 91 patients. Demographic information is included in the Baseline Characteristics Table 1.

There was no significant difference in age or gender between the two groups ( $\mathrm{p}=0.52$ and $\mathrm{p}=0.48$, respectively). The group of patients with infection had an approximately equal split for fractures and arthroplasties, whilst only $25 \%$ of patients in the group without infection had an arthroplasty. Within the group of patients with an infection, the most common organism cultured was Staphylococcus Aureus, accounting for nearly one-third of cases. A graph illustrating the proportion of organisms cultured in the group of patients with an infection is shown in Figure 1.

Mean serum 25[OH]D concentration was $59 \mathrm{nmol} / \mathrm{L}$ in the group without infection and $39 \mathrm{nmol} / \mathrm{L}$ in the group

Table I Baseline Characteristics

\begin{tabular}{|c|c|c|c|c|c|}
\hline \multicolumn{6}{|c|}{ Baseline Characteristics } \\
\hline & \multicolumn{2}{|c|}{ Group with Infection } & \multicolumn{2}{|c|}{ Group without Infection } & $P$ value \\
\hline Mean age (years) & \multicolumn{2}{|l|}{66} & \multicolumn{2}{|l|}{64} & 0.52 \\
\hline \multirow[t]{2}{*}{ Gender (\%) } & Male & Female & Male & Female & \multirow[t]{2}{*}{0.48} \\
\hline & 50 & 50 & 45 & 55 & \\
\hline \multirow[t]{2}{*}{ Orthopaedic condition } & Arthroplasty & Fracture & Arthroplasty & Fracture & \\
\hline & 50 & 50 & 25 & 75 & \\
\hline
\end{tabular}




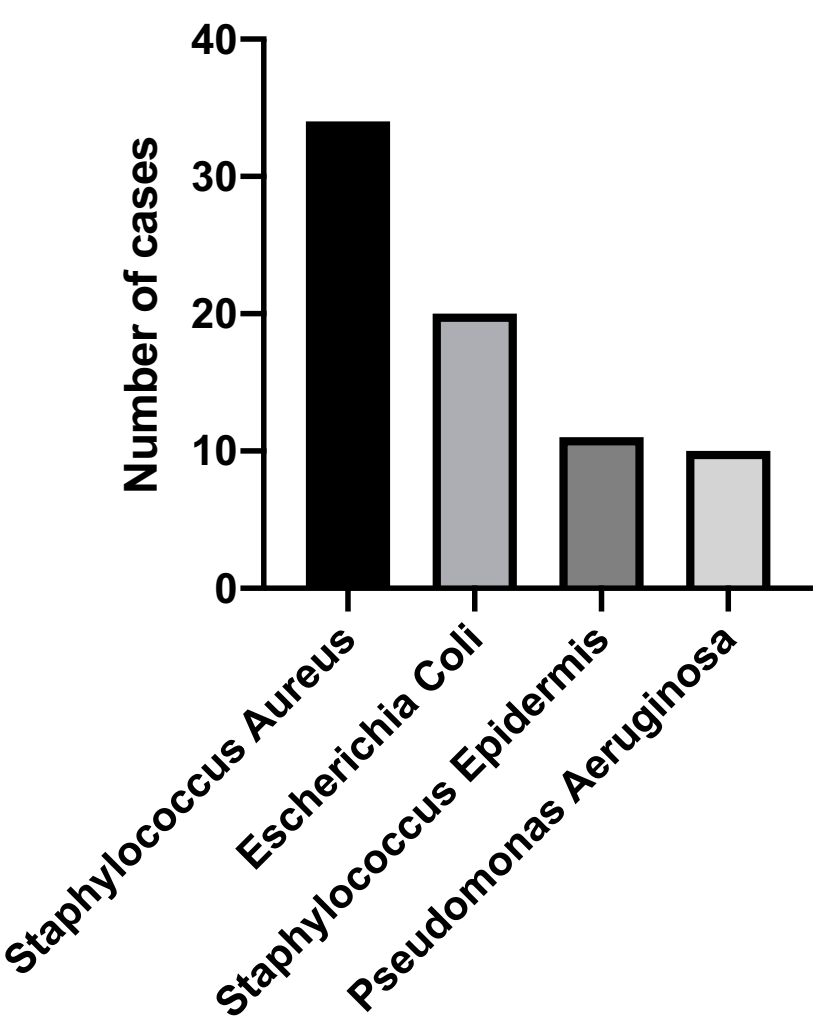

Organism

Figure I Graph of culture positive infections.

with infection $(\mathrm{p}<0.01)$. Mean serum 25[OH]D concentration across the total population was $48 \mathrm{nmol} / \mathrm{L}$. Figure 2 demonstrates a box-plot of the serum 25[OH]D levels found in the two groups and overall.

Serum 25[OH]D insufficiency was associated with increased infection (odds ratio, 5.94; 95\% confidence interval $[\mathrm{CI}], 3.24$ to 10.92). The Pearson Correlation coefficient between serum 25[OH]D concentration and infection was $-0.338(\mathrm{p}<0.01)$.

\section{Discussion}

Vitamin D is also known to be important in the field of Orthopaedic Surgery, due to its effect on bone density, with low levels of vitamin D resulting in rickets among children and osteomalacia among adults. However, there is less clarity surrounding the function of vitamin D in orthopaedic infection. Maier et al (2014) found severe vitamin D deficiency among patients with periprosthetic joint infections $(n=50)$ and those being treated with primary arthroplasties $(\mathrm{n}=109)$ in a single-centre study in Germany. ${ }^{16}$ However, this only takes into account patients with arthroplasties or joint

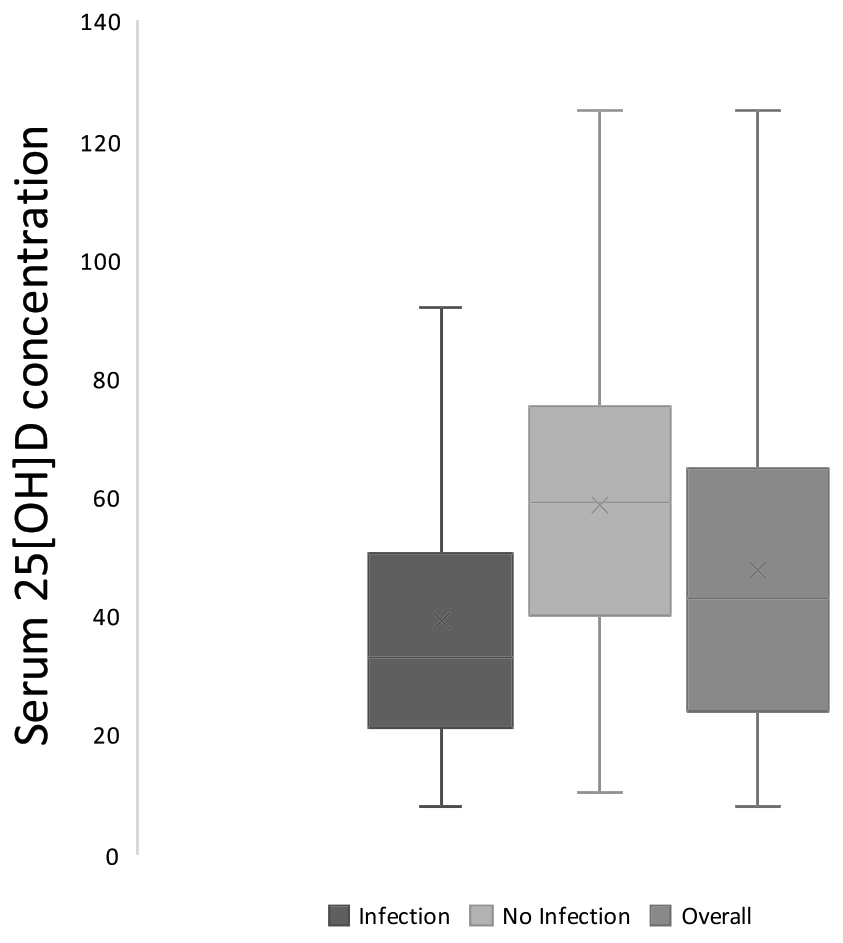

Figure 2 Box and whiskers diagram of $25[\mathrm{OH}] \mathrm{D}$ concentrations.

prosthesis, missing a significant proportion of orthopaedic inpatients. A further study of 1119 orthopaedic patients in Germany by the same authors found the prevalence of vitamin D insufficiency to be $84 \%$ and deficiency to be $60 \% .{ }^{17}$ However, vitamin D insufficiency is defined as a serum 25hydroxyvitamin D (25[OH]D) levels of $25-50 \mathrm{nmol} / \mathrm{L}$ and deficiency as serum 25[OH]D levels of less than $25 \mathrm{nmol} /$ L. ${ }^{18}$ In the study, the authors consider a normal value to be $>30 \mathrm{ng} / \mathrm{mL}$ which corresponds to $75 \mathrm{nmol} / \mathrm{L}$, meaning that a significant proportion of the population considered to have normal vitamin D levels in the UK would be categorised as having vitamin $\mathrm{D}$ insufficiency in the study.

Across the total population included in this study, the mean vitamin $\mathrm{D}$ level was insufficient at $48 \mathrm{nmol} / \mathrm{L}$. This value is slightly higher, but still in agreement with Maier et al $2013,{ }^{17}$ of $17.3 \mathrm{ng} / \mathrm{mL}$ which corresponds to $43 \mathrm{nmol} / \mathrm{L}$. This indicates that the orthopaedic population have insufficient levels of vitamin D and may benefit from supplementation.

The group of patients with an infection had a statistically significant mean of $20 \mathrm{nmol} / \mathrm{L}$ serum 25[OH]D concentration lower than the group of patients without an infection $(\mathrm{p}<0.01)$ suggesting that patients with lower levels of serum $25[\mathrm{OH}] \mathrm{D}$ concentration may be more susceptible to infection. This is also in agreement with the previous work conducted by Maier et al 2014, ${ }^{16}$ who found the 
mean serum $25[\mathrm{OH}] \mathrm{D}$ concentration in patients with a periprosthetic joint infection to be $13.29 \mathrm{ng} / \mathrm{mL}$, corresponding to $33.17 \mathrm{nmol} / \mathrm{L}$. This finding is reaffirmed by the finding in our study of a correlation of $-0.338(\mathrm{p}<0.01)$, and the odds ratio which suggests that lower levels of serum 25 $[\mathrm{OH}] \mathrm{D}$ are more likely to result in orthopaedic infection.

Whilst measures were taken to control for confounders such as seasonality, age and gender, it is important to acknowledge that causation cannot be inferred from these findings. Not all possible confounding factors were controlled for, including race, BMI and smoking status. Furthermore, the relationship of inflammation and low vitamin D levels may have impacted the results of this study. This study suggests that prophylactic supplementation of 25 $[\mathrm{OH}] \mathrm{D}$ may improve outcomes by reducing incidence of orthopaedic infection. However, a randomized controlled trial should be conducted before these findings are scaled into wider practice. Krakowska et al (2019) conducted a double-blind Randomized Controlled Trial into the effect of prophylactic vitamin D supplementation on pain and inflammatory markers after Posterior Lumbar Interbody Fusion Surgery, finding a significant reduction in both inflammatory markers and pain in the group of patients who had vitamin D supplementation. ${ }^{20}$ This supports our hypothesis that prophylactic supplementation of $25(\mathrm{OH}) \mathrm{D}$ may improve outcomes in orthopaedic surgery, but more work needs to be done to elucidate and quantify the benefit of prophylactic supplementation of vitamin D, as well as the optimum regimen.

Orthopaedic infection carries a high burden of morbidity to the patients, as well as cost to the health service, therefore measures must be taken to help reduce its incidence. Prophylactic supplementation with 25[OH]D could represent a simple yet very effective means of improving such outcomes, and this study provides a foundation upon which future trials can assess the efficacy of prophylactic supplementation in practice.

\section{Conclusion}

This study demonstrates an association between low levels of serum $25[\mathrm{OH}] \mathrm{D}$ and increased orthopaedic infection. Orthopaedic inpatients suffered from vitamin $\mathrm{D}$ insufficiency, and there was a correlation between higher levels of serum 25[OH]D and lower rates of infection. This suggests that prophylactic supplementation of 25 $[\mathrm{OH}] \mathrm{D}$ may improve outcomes, and provides a foundation for randomized controlled trials to assess its effectiveness in practice.

\section{Ethics}

Institutional Review Board: This study is registered with St George's University Hospitals NHS Foundation Trust Clinical Audit Office (REF: AUDI000664). Patient consent to review medical records was not required by the IRB, no identifiable patient information has been included in this study, patient data confidentiality was fully maintained at all times, and the study is compliant with the Declaration of Helsinki.

\section{Disclosure}

The authors report no conflicts of interest for this work.

\section{References}

1. Hyppönen E, Power C. Hypovitaminosis D in British adults at age 45 y: nationwide cohort study of dietary and lifestyle predictors. Am J Clin Nutr. 2007;85(3):860-868. doi:10.1093/ajcn/85.3.860

2. Pittas AG, Lau J, Hu FB, Dawson-Hughes B. The role of vitamin $\mathrm{D}$ and calcium in type 2 diabetes. A systematic review and meta-analysis. J Clin Endocrinol Metab. 2007;92(6):2017-2029. doi:10.1210/jc.2007-0298

3. Jablonski KL, Chonchol M, Pierce GL, Walker AE, Seals DR. 25Hydroxyvitamin D deficiency is associated with inflammation-linked vascular endothelial dysfunction in middle-aged and older adults. Hypertension. 2011;57(1):63-69. doi:10.1161/HYPERTENSIONAHA.110.160929

4. Apostolakis M, Armeni E, Bakas P, Lambrinoudaki I. Vitamin D and cardiovascular disease. Maturitas. 2018;115:1-22. doi:10.1016/j. maturitas.2018.05.010

5. Nitsa A, Toutouza M, Machairas N, Mariolis A, Philippou A, Koutsilieris M. Vitamin D in cardiovascular disease. In Vivo (Brooklyn). 2018;32(5):977-981. doi:10.21873/invivo.11338

6. Goyal H, Perisetti A, Rahman MR, Levin A, Lippi G. Vitamin D and gastrointestinal cancers: A narrative review. Dig Dis Sci. 2018.

7. Liu W, Zhang L, Xu H-J, et al. The anti-inflammatory effects of Vitamin D in tumorigenesis. Int J Mol Sci. 2018;19(9).

8. Wei H, Jing H, Wei Q, Wei G, Heng Z. Associations of the risk of lung cancer with serum 25 -hydroxyvitamin D level and dietary vitamin D intake: a dose-response PRISMA meta-analysis. Medicine. 2018;97(37):e12282. doi:10.1097/MD.0000000000012282

9. Fathi N, Ahmadian E, Shahi S, et al. Role of vitamin D and vitamin $\mathrm{D}$ receptor (VDR) in oral cancer. Biomed Pharmacother. 2019;109:391-401. doi:10.1016/j.biopha.2018.10.102

10. Bjelakovic G, Gluud LL, Nikolova D, et al. Vitamin D supplementation for prevention of mortality in adults. Cochrane Database Syst Rev. 2014;10(1):CD007470.

11. Martineau AR, Jolliffe DA, Hooper RL, et al. Vitamin D supplementation to prevent acute respiratory tract infections: systematic review and meta-analysis of individual participant data. $B M J$. 2017;15(356):i6583. doi:10.1136/bmj.i6583

12. de Haan K, Groeneveld ABJ, de Geus HRH, Egal M, Struijs A. Vitamin D deficiency as a risk factor for infection, sepsis and mortality in the critically ill: systematic review and meta-analysis. Crit Care. 2014;18(6):660. doi:10.1186/s13054-014-0660-4

13. Gombart AF. The vitamin D-antimicrobial peptide pathway and its role in protection against infection. Future Microbiol. 2009;4 (9):1151-1165. doi:10.2217/fmb.09.87

14. Quraishi SA, De Pascale G, Needleman JS, et al. Effect of cholecalciferol supplementation on vitamin d status and cathelicidin levels in sepsis: a randomized, placebo-controlled trial. Crit Care Med. 2015;43(9):1928-1937. doi:10.1097/CCM.0000000000001148 
15. Nair P, Venkatesh B, Lee $\mathrm{P}$, et al. A randomized study of a single dose of intramuscular cholecalciferol in critically ill adults. Crit Care Med. 2015;43(11):2313-2320. doi:10.1097/CCM.0000000000001201

16. Maier GS, Horas K, Seeger JB, Roth KE, Kurth AA, Maus U. Is there an association between periprosthetic joint infection and low vitamin D levels? Int Orthop. 2014;38(7):1499-1504. doi:10.1007/ s00264-014-2338-6

17. Maier GS, Jakobs P, Roth KE, Kurth AA, Maus U. Is there an epidemic vitamin D deficiency in German orthopaedic patients? Clin Orthop Relat Res. 2013;471(9):3029-3035. doi:10.1007/ s11999-013-2996-5
18. Kennel KA, Drake MT, Hurley DL. Vitamin D deficiency in adults: when to test and how to treat. Mayo Clin Proc. 2010;85(8):752-7; quiz 757. doi: $10.4065 / \mathrm{mcp} .2010 .0138$

19. Troughton R, Birgand G, Johnson AP, et al. Mapping national surveillance of surgical site infections in England: needs and priorities. $J$ Hosp Infect. 2018;100(4):378-385. doi:10.1016/j.jhin.2018.06.006

20. Krasowska K, Skrobot W, Liedtke E, et al. The preoperative supplementation with Vitamin D attenuated pain intensity and reduced the level of pro-inflammatory markers in patients after posterior lumbar interbody fusion. Front Pharmacol. 2019;10.

\section{Publish your work in this journal}

Orthopedic Research and Reviews is an international, peer-reviewed, open access journal that focusing on the patho-physiology of the musculoskeletal system, trauma, surgery and other corrective interventions to restore mobility and function. Advances in new technologies, materials, techniques and pharmacological agents are particularly welcome. The manuscript management system is completely online and includes a very quick and fair peer-review system, which is all easy to use. Visit http://www.dovepress.com/testimonials.php to read real quotes from published authors. 